\title{
Spatio-temporal Evolution of Water-Energy-Food System Risk from the Provincial Perspective: A Case Study of China
}

\author{
Tonghui Ding \\ Hohai University \\ Junfei Chen ( $\nabla$ chenjunfei@hhu.edu.cn ) \\ Hohai University \\ Ming Li \\ Data61
}

\section{Research Article}

Keywords: Water-energy-food system risk, Spatio-temporal evolution, Risk assessment, Set pair analysis, Risk matrix, China

Posted Date: January 20th, 2021

DOl: https://doi.org/10.21203/rs.3.rs-149849/v1

License: (a) (1) This work is licensed under a Creative Commons Attribution 4.0 International License. Read Full License 


\title{
Spatio-temporal Evolution of Water-Energy-Food
}

\section{System Risk from the provincial perspective: A case study of China}

\author{
Tonghui Ding ${ }^{a}$, Junfei Chen ${ }^{a, b, c, *}$, Ming $L^{d}$ \\ a Business School, Hohai University, Nanjing 211100, China \\ b Yangtze Institute for Conservation and Development, Hohai University, Nanjing 210098, \\ China \\ c Research Institute of Jiangsu Yangtze for Conservation and High-quality Development, \\ Nanjing 210098, China \\ d CSIRO Data61, Australian Resources Research Centre, Kensington WA 6151, Australia \\ * Corresponding author. \\ Email address: chenjunfei@hhu.edu.cn (Junfei Chen).
}

In this paper, the definition of Water-energy-food system risk (WEF-R) was firstly defined based on stability, coordination and sustainability. Set pair analysis and risk matrix were applied to assess the spatio-temporal dynamics of WEF-R in China from 2008 to 2017. The research results showed that stability subsystem had the greatest influence on the WEF-R, and sustainability subsystem was an important factor affecting the WEF-R. According to the spatial-temporal analysis, the risk levels of coordination and sustainable subsystems showed a gradual downward trend, while that of stability subsystem showed small fluctuations from 2008 to 2017. In terms of the WEF-R level, it presented a decreasing trend of small fluctuations. In addition, the higher-risk areas of stability subsystem and lower-risk areas of sustainability subsystem, which were mainly centralized in southeast coastal and central regions, were consistent with the areas of good economic development level and high level of urbanization. While the lower-risk areas of stability subsystem and higher-risk areas of sustainability subsystem, which were mainly centralized in the northwest regions, brought into correspondence with the areas of good resource endowment but lower levels of economic development. Therefore, the spatial differences of economic development level and resource endowment were the main factors affecting the spatial pattern of the WEF-R level in China. Therefore, policy makers should focus on WEF-R and implement measures to improve the sustainable development of WEF nexus.

Keywords: Water-energy-food system risk; Spatio-temporal evolution; Risk assessment; Set pair analysis; Risk matrix; China

Water resources, energy and food are important material resources to meet the most basic human requirements ${ }^{1}$. There has been a very sensitive and fragile relationship between water, energy and food ${ }^{2}$. The imbalance between supply and demand of water, energy and food is also prominent ${ }^{3-5}$ and water security, energy security and food security are facing greater security risks. In January 2011, in the Global Risk Report released by the World Economic Forum, "water-energy-food system risk (WEF-R)" was listed as one of the three key risks for the first time ${ }^{6-7}$. In November of the same year, the concept of water-energy-food nexus (WEF Nexus) was firstly addressed in the Bonn Conference 
and a wave of research has set off ${ }^{2}$. At present, China has become the world's largest consumer of water, energy and food, where energy and food are becoming more dependent on international markets. With the acceleration of urbanization, population growth and climate change, the pressure on resource supply inevitably increase, and the risks faced by water, energy and food exacerbate. Therefore, it is of great significance to carry out a comprehensive study on the WEF-R to ensure the water resource security, energy security and food security in China.

Many studies world-wide have focused on WEF nexus ${ }^{8-12}$, such as internal interaction mechanism ${ }^{13-15}$, security evaluation ${ }^{16}$, influential factors study ${ }^{17}$, optimization research ${ }^{18}$ and so on ${ }^{19-22}$. However, WEF-R assessment is often ignored in WEF studies. Most researches about resources risk are mainly assessed from the perspective of single resource or two resources ${ }^{23-26}$. Lal systematically constructed the framework of water shortage risk based on WEF nexus ${ }^{27}$. Chen thought that WEF-R on the urban scale was composed of "demand risk" and "bond risk"28.

The aim of this study was to analyze and assess the WEF-R with China as the research object and to carry out scenario simulation. Specific objectives of the study were to define the definition of the WEF-R and establish a risk evaluation index system, then to assess the WEF-R by using set pair analysis and risk matrix.

\section{Study area}

China, located in the northern half of the Eastern Hemisphere, the eastern part of Eurasia and the western part of the Pacific Ocean, has jurisdiction of 34 provinces (including Beijing, Shanghai and Jiangsu etc,), with a total area of $9,600,000 \mathrm{~km}^{2}$ (as shown in Fig.1). China has $1 / 6$ of the world's total fresh water resources, but its water resources per capita are less than $2,400 \mathrm{~m}^{3}$ and there are huge differences in the spatial distribution of water resources. The energy demand in China is growing rapidly, where energy consumption was 4,485,291,400 tons of standard coal, accounting for 23.2 percent of the world's total in 2017. In addition, due to the spatial difference of energy storage and imbalance of energy consumption, there is a wide discrepancy for regional energy pressure. Food development is also facing severe challenges in China, where arable land area only accounts for $7 \%$ of the world's total. In 2017, China's total food acreage was 166,333 hectares, while the food production per capita was only $476 \mathrm{~kg}$. Besides, with the impact of global climate change in recent years, the phenomenon of drought occurs frequently all over China, which has caused serious food security problems. Therefore, the assessment of WEF-R in China is of great importance.

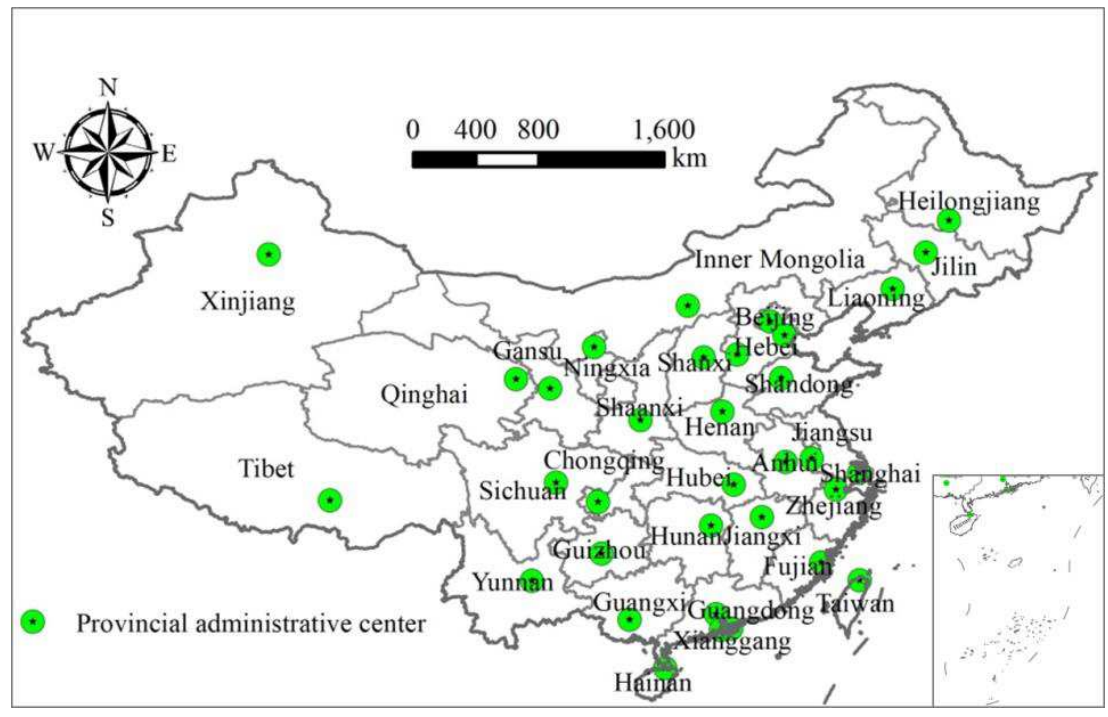

Fig. 1. Geographic location of China 


\section{Definition of WEF-R}

The WEF nexus security is not only affected by the risk elements within the WEF system, but affected by the efficiency of resource conversion. At the same time, the WEF nexus security is also influenced by the potential threats from the risk factors such as natural environment, human society and economic development. Therefore, this paper defines the WEF-R from the perspectives of stability, coordination and sustainability by referring to relevant literature ${ }^{29}$ ( as shown in Fig. 2). Stability measures the quantity, quality, structure and function of the internal resources of water resources subsystem, energy subsystem and food subsystem, that is the "internal risks" of WEF nexus security, such as water resources, energy and food shortage. Coordination refers to the allocation and utilization efficiency of water-energy, water-food and energy-food conversion process, namely the "nexus risk" of WEF nexus security, such as low conversion efficiency of water-energy, water-food and energy-food. Sustainability means the interaction between the WEF system, Socio economic system and natural environment system, namely the "external risk" of WEF nexus security. When the development of external social economy and the state of natural environment affect and pressure on WEF systems, which exceed the allowable range of WEF nexus, it will form risks to the WEF nexus security, such as natural disasters, water loss and soil erosion, air pollution, etc.

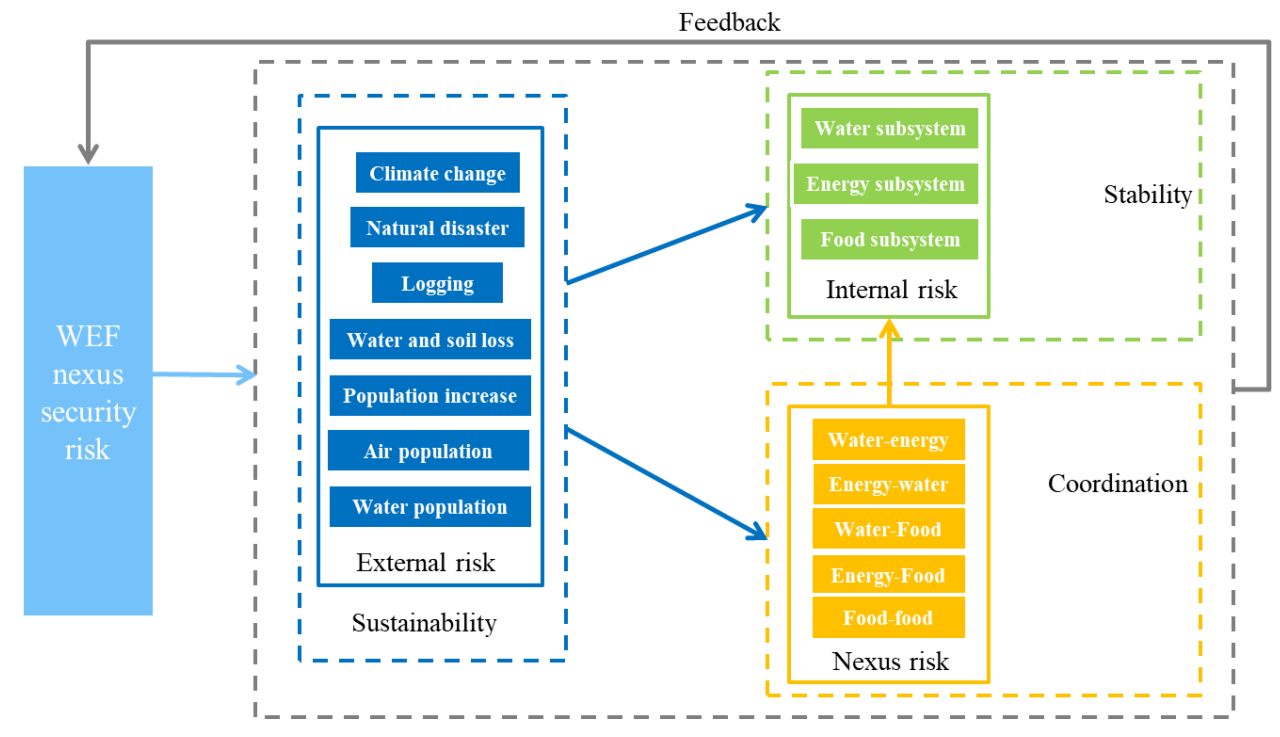

Fig. 2. The concept diagram of WEF-R

\section{Risk evaluation index system}

Establishment of the risk evaluation index system is fundamental for the assessment of WEF-R. According to the definition of WEF-R, the risk evaluation index system, which covers stability subsystem, coordination subsystem and sustainability subsystem, was then developed. The risk evaluation index system contains four layers: the object layer, the first layer, elements layer and the second layer. The risk evaluation index system of WEF nexus is the object layer, and the first layer includes stability subsystem, coordination subsystem and sustainability subsystem. In addition, the second layer contains various factors that apply to the first layer. Finally, basing on the principles of scientific, integrity, dynamics and data availability ${ }^{30}$, and referring to relevant literature and experts' suggestions, twenty-nine indices were selected (Table 1). Grade criteria system is very important for WEF-R assessment. In this paper, risk grade was divided into five levels, grade I (lowest risk), grade II (lower risk), grade III (moderate risk), grade IV (higher risk), grade V (highest risk) respectively ${ }^{31}$. By 
referring to relevant literatures, integrating the national average level, the development level of developed and underdeveloped regions, this paper determines the interval range of each index of risk evaluation index system (Table S2).

Table 1. Risk evaluation index system of WEF-R in China

\begin{tabular}{|c|c|c|c|c|}
\hline $\begin{array}{l}\text { Object } \\
\text { layer }\end{array}$ & $\begin{array}{l}\text { The first } \\
\text { layer }\end{array}$ & $\begin{array}{l}\text { Elements } \\
\text { layer }\end{array}$ & $\begin{array}{l}\text { The second } \\
\text { layer }\end{array}$ & Unit \\
\hline \multirow{29}{*}{$\begin{array}{l}\text { The risk } \\
\text { evaluation } \\
\text { index } \\
\text { system of } \\
\text { WEF-R }\end{array}$} & \multirow{12}{*}{$\begin{array}{l}\text { Stability } \\
\text { subsystem }\end{array}$} & \multirow{3}{*}{$\begin{array}{l}\text { Water } \\
\text { system }\end{array}$} & $\mathrm{C}_{1}:$ Water resources per capita & $\mathrm{m}^{3}$ \\
\hline & & & $\mathrm{C}_{2}$ : Utilization rate of water resources development & $\%$ \\
\hline & & & $\mathrm{C}_{3}$ : Utilization rate of groundwater resources & $\%$ \\
\hline & & \multirow{3}{*}{$\begin{array}{l}\text { Energy } \\
\text { system }\end{array}$} & $\mathrm{C}_{4}$ : Energy production per capita & $\begin{array}{l}\text { Tons of } \\
\text { standard coal }\end{array}$ \\
\hline & & & $\mathrm{C}_{5}$ : Elasticity of energy consumption & - \\
\hline & & & $\mathrm{C}_{6}$ : Energy self-sufficiency rate & $\%$ \\
\hline & & \multirow{3}{*}{$\begin{array}{l}\text { Food } \\
\text { system }\end{array}$} & $\mathrm{C}_{7}:$ Food production per capita & $\mathrm{kg}$ \\
\hline & & & $\mathrm{C}_{8}$ : Arable land per capita & $\mathrm{m}^{2}$ \\
\hline & & & $C_{9}:$ Food production per unit area & $\mathrm{kg} / \mathrm{m}^{2}$ \\
\hline & & \multirow{4}{*}{ Water-energy } & $C_{10}:$ Water consumption per unit energy production & $\begin{array}{l}\mathrm{m}^{3} / \text { Tons of } \\
\text { standard coal }\end{array}$ \\
\hline & & & $\mathrm{C}_{11}$ : Proportion of industrial water consumption & $\%$ \\
\hline & & & $C_{12}:$ Water consumption per $10^{4}$ yuan industrial output & $\mathrm{m}^{3} / 10^{4}$ yuan \\
\hline & \multirow{4}{*}{$\begin{array}{l}\text { Coordination } \\
\text { Subsystem }\end{array}$} & & $\mathrm{C}_{13}$ : Proportion of agricultural water consumption & $\%$ \\
\hline & & \multirow{4}{*}{ Water-food } & $\mathrm{C}_{14}$ : Agricultural irrigation quota & $\mathrm{m}^{3} / \mathrm{mu}$ \\
\hline & & & $C_{15}$ : Water consumption per $10^{4}$ yuan agricultural output & $\mathrm{m}^{3} / 10^{4}$ yuan \\
\hline & & & $C_{16}$ : The effective irrigation rate of cultivated land & $\%$ \\
\hline & & & $\mathrm{C}_{17}:$ Farm machinery power per unit cultivated area & $\mathrm{kw} / \mathrm{ha}$ \\
\hline & \multirow{12}{*}{$\begin{array}{l}\text { Sustainability } \\
\text { subsystem }\end{array}$} & Energy-food & $\begin{array}{l}\mathrm{C}_{18}: \text { Proportion of energy consumption in the primary } \\
\text { industry }\end{array}$ & $\%$ \\
\hline & & \multirow{4}{*}{$\begin{array}{l}\text { Economy } \\
\text { system }\end{array}$} & $\mathrm{C}_{19}: \mathrm{GDP}$ per capita & $10^{4}$ Yuan \\
\hline & & & $C_{20}:$ Water consumption per $10^{4}$ yuan GDP & $\mathrm{m}^{3}$ \\
\hline & & & $C_{21}$ :Energy consumption per $10^{4}$ yuan GDP & $\begin{array}{l}\text { Tons of } \\
\text { standard coal }\end{array}$ \\
\hline & & & $\mathrm{C}_{22}$ : Population growth rate & $\%$ \\
\hline & & \multirow{3}{*}{$\begin{array}{l}\text { Social } \\
\text { system }\end{array}$} & $\mathrm{C}_{23}$ : Urbanization rate & $\%$ \\
\hline & & & $\mathrm{C}_{24}$ : Population density & $\begin{array}{l}\text { Population/ } \\
\mathrm{km}^{2}\end{array}$ \\
\hline & & & $\mathrm{C}_{25}:$ Annual precipitation & $\mathrm{mm}$ \\
\hline & & \multirow{4}{*}{$\begin{array}{l}\text { Natural } \\
\text { system }\end{array}$} & $\mathrm{C}_{26}$ : Utilization rate of industrial solid waste & $\%$ \\
\hline & & & $\mathrm{C}_{27}$ : Forest coverage rate & $\%$ \\
\hline & & & $\mathrm{C}_{28}:$ Fertilizer load & Ton/ha \\
\hline & & & $C_{29}$ : Greenhouse gas emissions per $10^{4}$ yuan GDP & $\mathrm{kg} / 10^{4}$ yuan \\
\hline
\end{tabular}




\section{Results}

The weights of indexes and subsystems. Entropy weight method was applied to evaluate the weight of indexes and subsystems for risk evaluation system of WEF nexus from 2008 to 2017. Weight 1 and weight 2 in 2017 was shows (Table S3). Weight 1 referred to taking stability, coordination and sustainability as three subsystems to calculate the weight of each index of each subsystem. Weight 2 was to take stability, coordination and sustainability as a whole to calculate the weight of each index and then obtained the weight of each subsystem by sum the weight of each index, which was provided a judgment basis for the risk matrix.

According to the results of the weight 2, it can be obtained that the weights of stability, coordination and sustainability subsystems were $0.4269,0.2114$ and 0.2959 respectively. Therefore, it could be indicated that stability, which was the main cause of WEF-R, had the greatest influence on WEF-R. Sustainability was an important factor affecting the WEF nexus, while coordination had the least impact on WEF-R. Additionally, it can be revealed from the weight 1 that indices $\mathrm{C}_{1}$ (water resources per capita) and $\mathrm{C}_{4}$ (energy production per capita) had more apparent influence on risk levels of stability subsystem, $C_{16}$ (The effective irrigation rate of cultivated land) and $C_{17}$ (Farm machinery power per unit cultivated area) had a significant impact on risk levels of coordination subsystem, while $\mathrm{C}_{19}$ (GDP per capita) and $\mathrm{C}_{26}$ (Utilization rate of industrial solid waste) had an important impact on risk levels of sustainability subsystem.

The analysis of risk assessment results. Based on the weight vectors of WEF nexus, the set pair analysis and risk matrix could be applied to assess the WEF-R in 30 provinces of China from 2008 to 2017. The risk levels of stability, coordination and sustainability subsystems in 2008, 2013 and 2017 were showed (Table S4). Then the risk matrix was used to synthesize the risk levels of WEF nexus (Table S5).

It can be concluded that, (1) As for stability subsystem, in 2008, 2013 and 2017, the numbers of provinces with the lowest risk were $0,1,0$. The numbers of provinces with lower risk were $3,3,3$. The numbers of provinces with moderate risk were $8,10,10$. The numbers of provinces with higher risk were $15,13,14$. The numbers of provinces with the highest risk were $4,3,3$. So it showed that the higher and highest risks reduced year by year, while those with moderate risk presented the increasing trend. It can be seen that as the time went by, the government was also taking active measures to curtail the problems, such as water shortage, energy depletion and arable land decrease, to improve the efficiency of resource utilization. (2) As for coordination subsystem, the numbers of provinces with the lowest risk were $0,0,0$. The numbers of provinces with lower coordination risk were 1, 1, 2. The numbers of provinces with moderate risk were $3,6,6$. The numbers of provinces with higher risk were $21,21,21$. The numbers of provinces with highest risk were $5,2,1$. Therefore, the numbers of provinces with the highest risk decreased year by year, while the moderate risk gradually increased. Additionally, the numbers of provinces with higher risk were always 21 , accounting for $70 \%$ of the whole provinces in China, indicating that the overall coordination degree of WEF nexus in China is not high. (3) As for sustainability subsystem, the numbers of provinces with the lowest and highest risk were both $0,0,0$. The numbers of provinces with lower risk were $3,8,9$. The numbers of provinces with moderate risk were $12,15,12$. The numbers of provinces with higher risk were $15,7,9$. Thus, the numbers of provinces with lower risk provinces increased year by year, while higher risk gradually decreased. The risk levels of WEF sustainability subsystem in China gradually shift from higher risk to lower risk. (4) As for the WEF-R, the numbers of provinces with the lowest risk were $0,0,0$. The numbers of provinces with lower risk were $0,0,1$. The numbers of provinces with moderate risk were 
$12,17,18$. The numbers of provinces with higher risk were $17,12,11$. The numbers of provinces with highest risk were $1,0,0$. This is indicated that the numbers of provinces with moderate risk increase gradually, while higher risk decline little by little.

In summary, the numbers of provinces with the higher and highest risks of three subsystems decreased year by year, while moderate and lower risks increased with each passing year. Due to the risk changes of the stability, coordination and sustainability subsystems, WEF-R levels in China were gradually reduced from higher to moderate.

\section{Discussion}

Spatial analysis of WEF-R. Based on risk assessment results, the spatial distributions of the risk levels of stability, coordination, sustainability subsystems and WEF-R for all provinces in China were shown in Fig. 3-6.

(1) Risk level of stability subsystem.

Fig. 3 showed the spatial distribution of risk level of WEF stability subsystem in 30 provinces of China in 2008, 2013 and 2017. It could be concluded that risk level of stability subsystem in China decreased year by year. And the higher-risk areas of WEF stability subsystem were mainly centralized in southeast coastal and central regions, which were consistent with the areas of good economic development level and high level of urbanization. With the time going, the risks were gradually gathering to the east, such as Beijing, Shanghai, Jiangsu, south of the Yangtze River. Taking Beijing as an example, its water resources are mainly dependent on the supply of South-North Water Transfer Project, while its energy and food mainly rely on external transfer. As a result, the supply of its water resources, energy and food are greatly affected by external risk factors. In addition, lower risk areas of WEF stability subsystem were concentrated in the western region, which brought into correspondence with the areas of good resource endowment but lower economic development levels, such as Inner Mongolia, Xinjiang, and Qinghai. Taking Inner Mongolia as an example, Inner Mongolia is a big province of energy production and consumption in China, which not only rich in coal, oil, natural gas, but also has a good utilization prospects for the use of wind, solar, biomass and other clean energy. Therefore, Inner Mongolia has strong stability of energy resources.
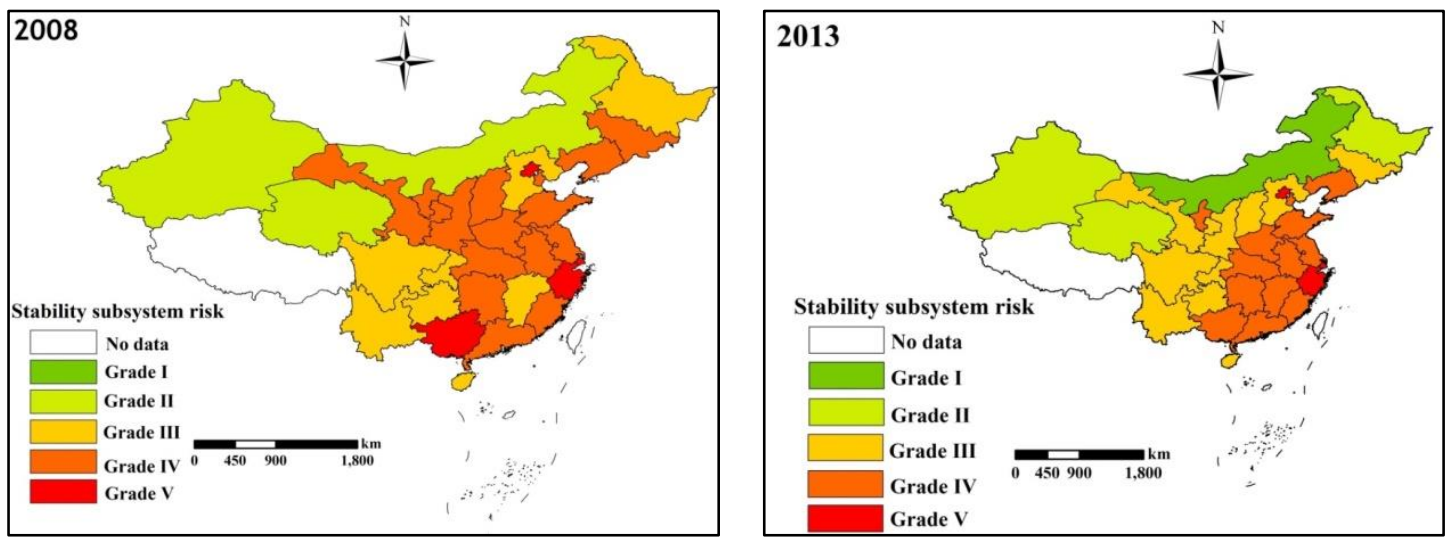


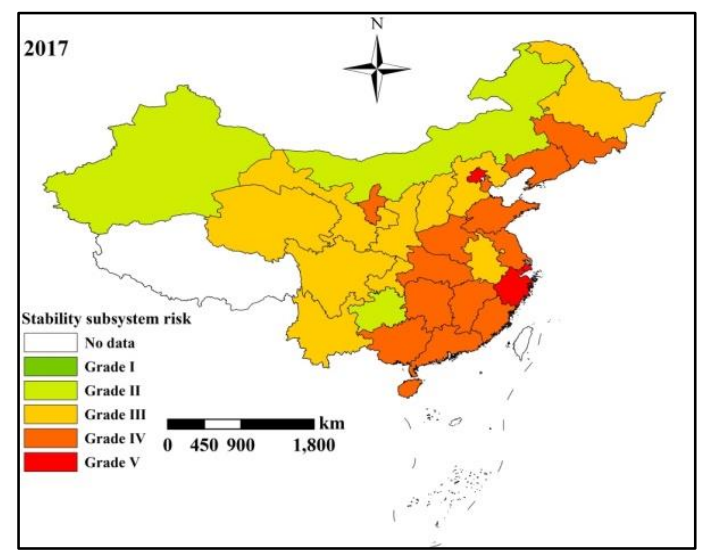

Fig. 3. The spatial distribution of risk level of WEF stability subsystem in 30 provinces of China in 2008, 2013, and 2017

(2) Risk level of coordination subsystem.

Fig. 4 showed the spatial distribution of risk level of WEF coordination subsystem in 30 provinces of China in 2008, 2013 and 2017. It could be seen that risk level of coordination subsystem in China gradually declined. And provinces with lower and moderate risks were mainly concentrated in eastern areas, such as Beijing, Tianjin and Hebei. In addition, the risk levels of coordination subsystem in most provinces of China were grade IV (such as Xinjiang, Inner Mongolia, Qinghai, etc. ), indicating that the WEF nexus in China was not well coordinated on the whole, the conversion efficiency of water resources, energy and food was low, and the technical level of resource conversion needed to be improved. Therefore, provinces in China should improve the allocation and utilization efficiency of resources, alleviate the pressure of water resources, increase the added value of energy and food supply, and reduce environmental pollution based on agricultural water-saving, industrial upgrading and process optimization.
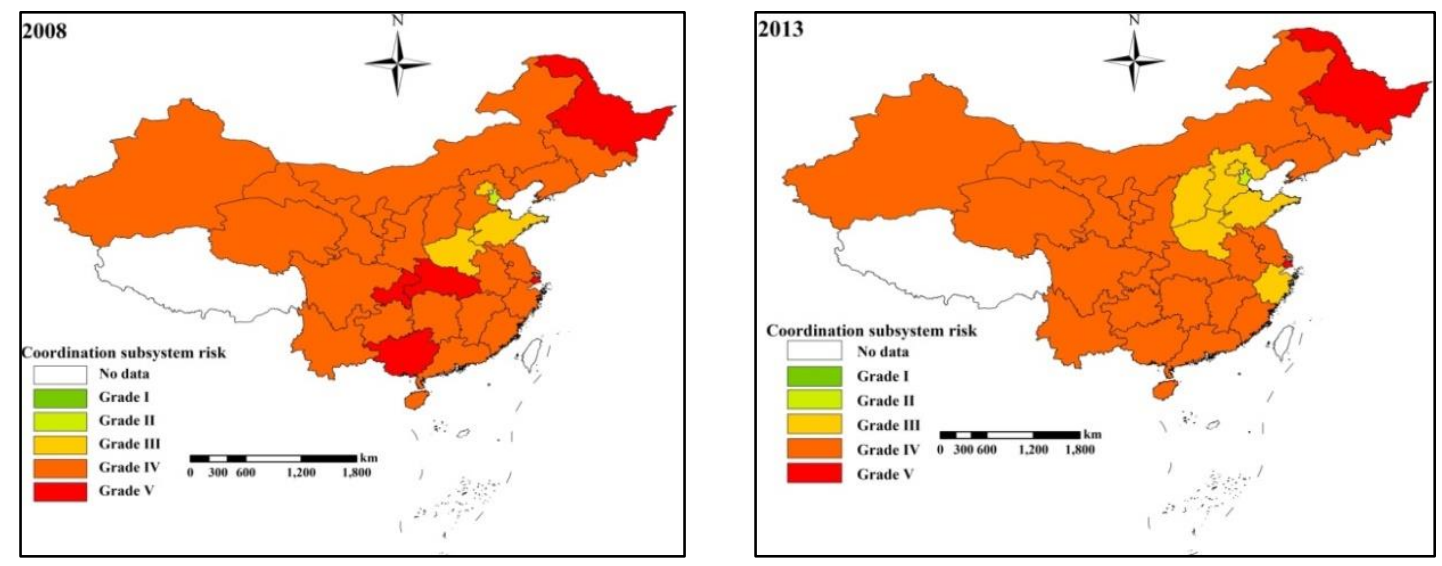


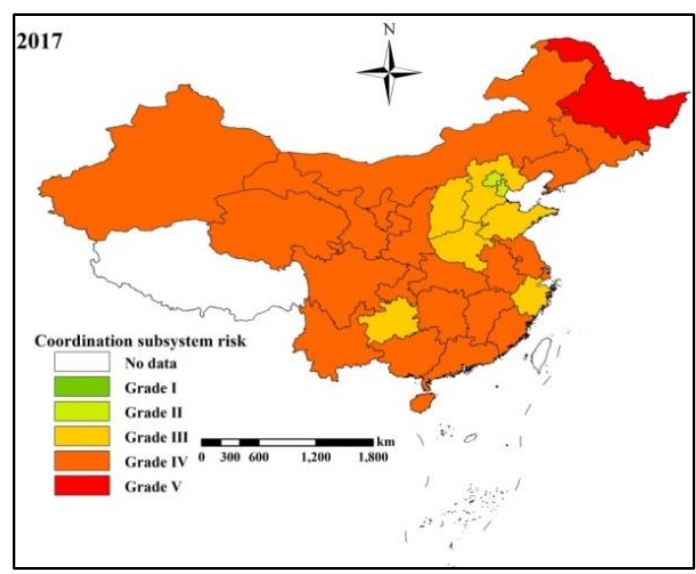

Fig. 4. The spatial distribution of risk level of WEF coordination subsystem in 30 provinces of China

(3) Risk level of sustainability subsystem.

Fig. 5 showed the spatial distribution of risk level of WEF sustainability subsystem in 30 provinces of China in 2008, 2013 and 2017. It could be revealed that risk level of sustainability subsystem in China decreased year by year. And the provinces with lower risk were mainly concentrated in the southeast coastal, such as Shanghai, Jiangsu, Zhejiang, etc. It can be seen that provinces with lower risks were consistent with the areas of good economic development level and high level of urbanization in China, while those of higher risks brought into correspondence with the areas of good resource endowment but backward economic level. The provinces with moderate risks were scattered, mainly in Heilongjiang, Jilin, Liaoning, Shandong, Shaanxi, Henan, Anhui, Hubei, Sichuan and Yunnan. And provinces with higher risk were primarily distributed in northwest China.
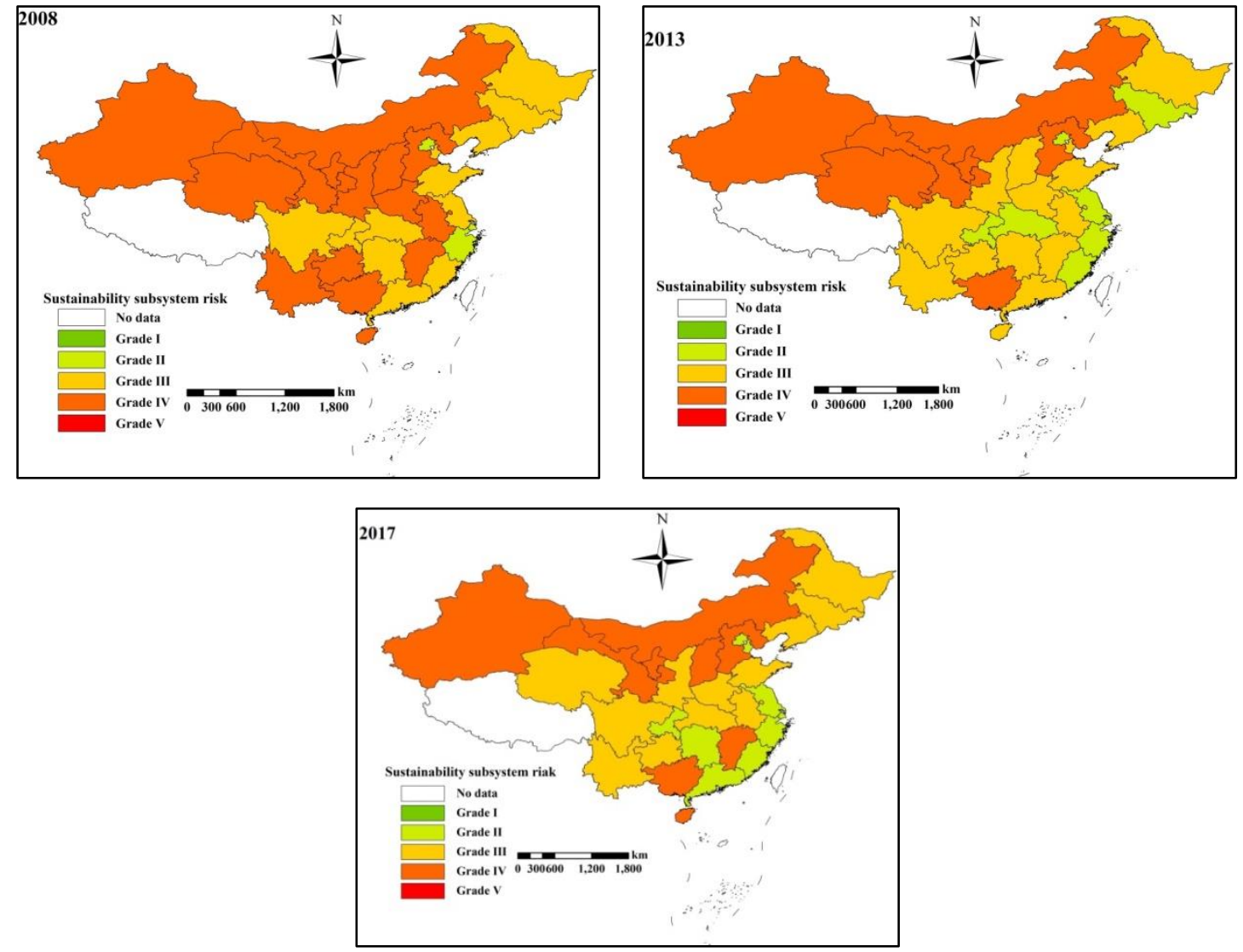

Fig. 5. The spatial distribution of risk level of WEF sustainable subsystem in 30 provinces of China 
(4) WEF-R levels.

Fig. 6 showed the spatial distribution of WEF-R levels in 30 provinces of China in 2008, 2013 and 2017. It could be concluded that WEF-R levels in China were primarily Grade III (moderate risk) and Grade IV (higher risk). In addition, the numbers of provinces with higher risk decreased year by year. By 2017, only Jilin, Liaoning, Shandong, Ningxia, Henan, Hubei, Zhejiang, Jiangxi, Guangxi, Hainan and Shanghai rated their WEF nexus as higher risk, while the others were moderate risk or lower risk. Therefore, it is necessary for China to take measures to reduce WEF-R levels.

To sum up, risk levels of three subsystems and WEF-R levels in China were all decreasing from 2008 to 2017. However, the total WEF-R levels still remained high from 2008 to 2017. Additionally, the spatial differences of economic development level and resource endowment are the main factor affecting the spatial pattern of WEF-R levels in China.
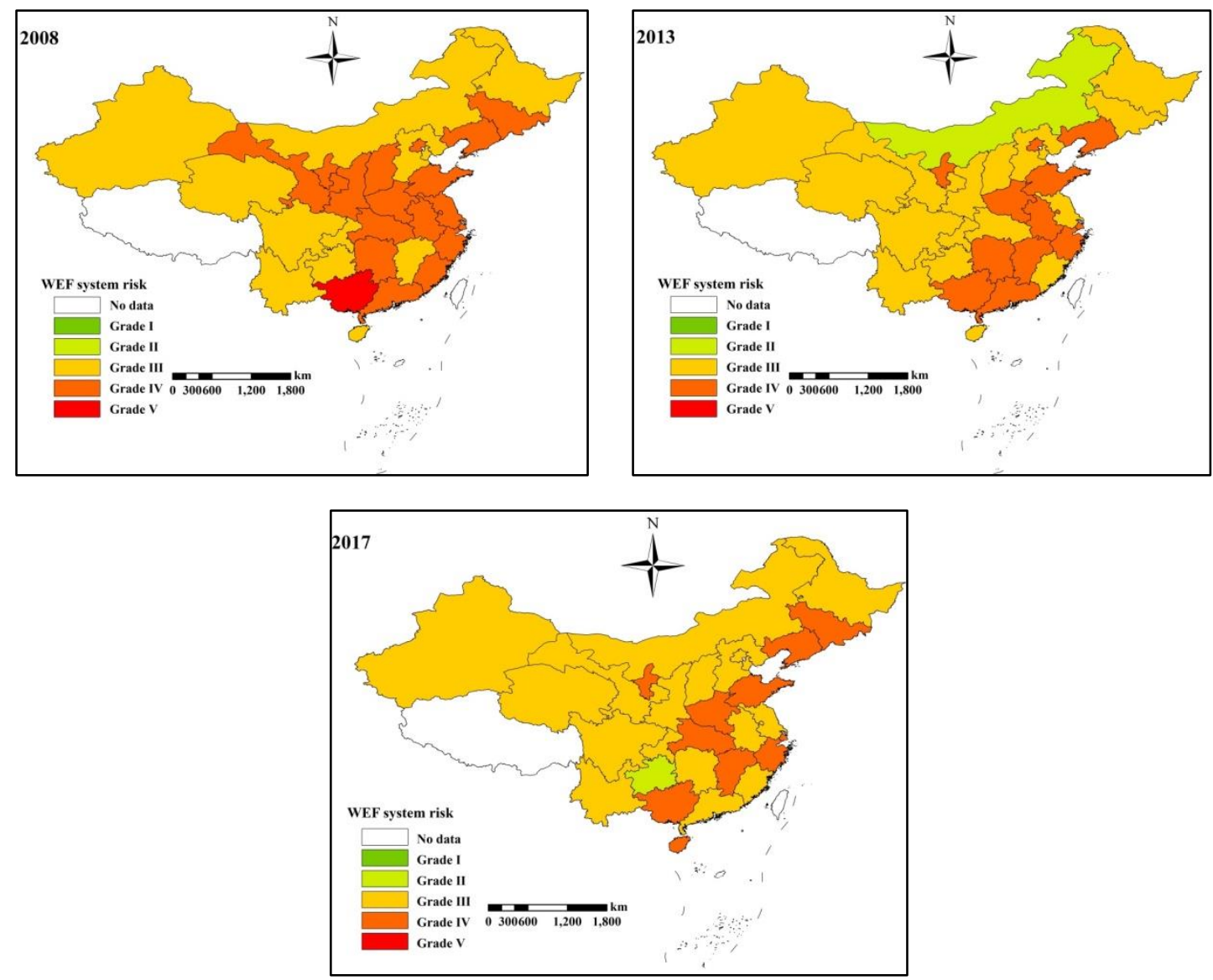

Fig. 6. The spatial distribution of WEF-R levels in 30 provinces of China

Temporal analysis of WEF-R. Based on risk assessment results of each province, risk levels at the country scale can be obtained by calculating the average value from 2008 to 2017, then the change trend of risk levels of three subsystems and WEF-R was drawn (as shown in Fig. 7). It could be evidently revealed that, (1) By observing the change trend of risk levels of stability, coordination and sustainable subsystems from 2008 to 2017, it can be found that the risk level of stability subsystem showed small fluctuations. While the risk level of coordination subsystem showed a downward trend, but the decline was not large. The main reason is that with the continuous improvement of management and technology, the absolute quantity representing the degree of transformation and utilization of resources increases, but slowly due to the constraints of resource endowment and external environment. And the risk level of sustainable subsystem showed a gradual downward trend 
from 2008 to 2017, which declined from 2008 to 2013, then fell further from 2015 to 2016. And there was a small increase from 2013 to 2015 and from 2016 to 2017, but there was a downward trend on the whole. It is because the government starts to attach importance to the WEF nexus security with the development of resource-saving, environment-friendly society and the concept of ecological civilization. (2) WEF-R levels presented a decreasing trend of small fluctuation in China from 2008 to 2017, declining with the annual rate of $3 \%$. It is illustrated that with the deepening understanding of the importance of WEF nexus, the government and all sectors actively adopt reliable measures to improve the efficiency of development, transformation and utilization of water, energy and food to guarantee the WEF nexus security.

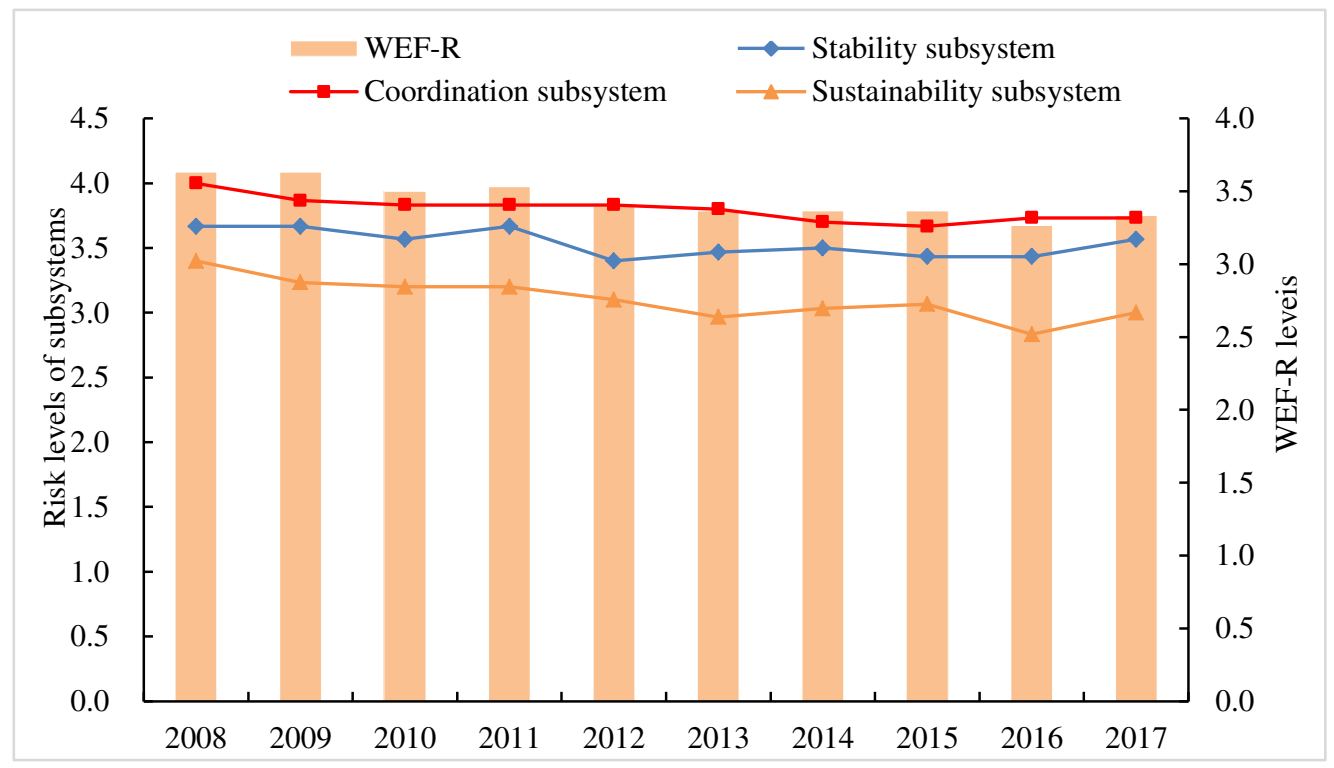

Fig. 7. The change trend of risk levels of three subsystems and WEF-R in China from 2008 to 2017

\section{Conclusion}

The results showed that the stability subsystem had the greatest influence on the WEF-R, and sustainability subsystem was a significant factor affecting the WEF-R. The spatial differences of economic development level and resource endowment were the main factors affecting the spatial pattern of WEF-R levels in China. In addition, temporal analysis showed that the risk levels of coordination subsystem and sustainable subsystem showed a gradual downward trend from 2008 to 2017, while the risk level of stability subsystem showed small fluctuations. In terms of WEF-R levels, it presented a decreasing trend of small fluctuation from 2008 to 2017.

\section{Methods}

Set Pair Analysis. Set Pair Analysis, proposed by Zhao from China ${ }^{32}$, is a combination of probability analysis and uncertainty analysis. The basis of set pair analysis is set pair and its key is connection degree. Assuming that set $A$ and a relative set $B$ are combined to form a set pair $H(A, B)$. In order to study the relationship and judge the good or bad degree of the set pair $H(A, B)$.

Risk matrix. Risk matrix, proposed by U.S. Air Force Electronic Systems Center in the late 1990s, is applied to recognize the ultimate risk assessment result by qualitatively and quantitatively analyzing the occurring possibilities of risk events and potential impacts ${ }^{33}$. The core principles of risk matrix include potential impact evaluation of risk factors, possibility calculation for the occurring of risk events, grade evaluation of risk event and countermeasure establishment of risk management. In 
order to evaluate the WEF security nexus risk effectively, scholars must focus on the main risk factors and construct the final risk matrix by analyzing, ranking and comparing the importance of different risk factors. The risk matrix of WEF-R assessment (Table S1) could be employed to determine the overall risk grade of WEF system basing on the determination of risk grade for each subsystem.

\section{References}

1. Yan, X.X. et al. Assessment of Sweet Sorghum-Based Ethanol Potential in China within the Water-Energy-Food Nexus Framework. Sustainability 10, 1046-1063 (2018).

2. Hoff, H. Understanding the nexus. Background paper for the Bonn 2011 conference: the water energy and food security nexus. Stockholm Environment Institute (SEI). Stockholm, Sweden. (2011).

3. FAO. The Water-energy-food Nexus: a New Approach in Support of Food Security and Sustainable Agriculture. Rome. (2014).

4. Wang, H.M., Hong, J. \& Liu, G. Simulation research on different policies of regional green development under the nexus of water-energy-food. China population Resour. Environ. 29, 74-84 (2019). (in Chinese).

5. Keairns, D.L., Darton, R.C. \& Irabien, A. The energy-water-food nexus. Annual review of chemical and biomolecular engineering 7, 239-262 (2016).

6. World Economic Forum. Global Risks 2011 Report (6th edition). Cologne: World Economic Forum (2011).

7. Food and Agriculture Organization of the United Nations. The water-energy-food nexus: a new approach in support of food security and sustainable agriculture. Italy, Rome (2014).

8. Xiang, X. Z. \& Jia, S.F. China's water-energy nexus: Assessment of water-related energy use. Resour. Conserve. Recycl. 144, 32-38 (2019).

9. Guo, Y., Tian, J.P. \& Chen, L.J. Water-energy nexus in China's industrial parks. Resour. Conserv. Recycl. 153, 1-8 (2020).

10. Zeng, X.T. et al. Scenario analysis of a sustainable water-food nexus optimization with consideration of population-economy regulation in Beijing-Tianjin-Hebei region. J. clean. Prod. 228, 927-940 (2019).

11. Balda, M.C. \& Kawajiri K. The right crops in the right place for the food-energy nexus: Potential analysis on rice and wheat in Hokkaido using crop growth models. J. clean. Prod. 263, 1-7 (2020).

12. Ladha-sabur, A. et al. Mapping energy consumption in food manufacturing. Trends in Food Sci. \& Technology. 86, 270-280 (2019).

13. Daohan, H. et al. Exploring interactions in the local water-energy-food nexus (WEF-Nexus) using a simultaneous equations model. Sci of the total Environ. 703, 1-12 (2020).

14. Zhi, Y.L. et al. Assessment of water-energy-food nexus fitness in China from the perspective of symbiosis. China population Resour. Environ. 30, 129-139 (2020). (in Chinese)

15. Mahlknecht, J. \& González-Bravo, R. Measuring the Water-Energy-Food Nexus: The Case of Latin America and the Caribbean Region. Energy Procedia. 153, 169-173 (2018).

16. Bizikova, L. et al. The water-energy-food security nexus: towards a practical planning and decision-support framework for landscape investment and risk management. International Institute for Sustainable Development (IISD), Manitoba. (2013).

17. Chen, J.F., Ding, T.H. \& Wang, H.M. Research on total factor productivity and influential factors of regional Water-Energy-Food: A case study of Inner Mongolia. Int. J. Environ. Res. Public Health. 16, 3051-3075 (2019).

18. Chen, J.F., Ding, T.H. \& Li, M. Multi-objective optimization of a regional water-energy-food system 
considering environmental constraints: A case study of Inner Mongolia, China. Intern. J. Environ. Res. Public Health 18, 6834-6856 (2020).

19. Wolfe, M.L. et al. Engineering solutions for food-energy-water systems: it is more than engineering. J. Environ. Studies \& Sci. 6, 172-182 (2016).

20. Kurian, M. The water-energy-food nexus: Trade-offs, thresholds and transdisciplinary approaches to sustainable development. Environ. Sci. \& Policy 68, 97-106 (2017).

21. Mo, L. et al. Stochastic multi-objective modeling for optimization of water-food-energy nexus of irrigated agriculture. Advance in Water Resour. 127, 209-224 (2019).

22. Purwanto, A. et al. Using group model building to develop a causal loop mapping of the water-energy-food security nexus in Karawang Regency, Indonesia. J. Clean. Prod. 240,118170 (2019).

23. Sun, C. et al. Water risk assessment and spatial correlation patterns research in provincial scale in China. Water Resour. Protection 6, 18-26 (2015).

24. Xiao, Z.Y., Gao, J. \& Su, Y. China's water risk assessment and industrial source analysis based on the localization of WWF water risk assessment tools. Environ. Impact Assessment Review 78, 195-206 (2019).

25. Wu, Y.N., Liu, P. \& Chen, J.S. Food safety risk assessment in China: Past, present and future. Food Control 90, 212-221 (2019).

26. Cai, Y.P. et al. Integrated risk analysis of water-energy nexus systems based on systems dynamics, orthogonal design and copula analysis. Renewable and Sustainable Energy Reviews 99, 125-137 (2019).

27. Lal, R. Research and development priorities in water security. Agronomy J. 107, 1567-1572 (2015).

28. Chen, I.C. et al. Assessing the risk of the food-energy-water nexus of urban metabolism: A case study of Kinmen Island, Taiwan. Ecological Indicators. 110, 1470-1480 (2020).

29. Chen, J.F. et al. Study on vulnerability and coordination of Water-Energy-Food system in Northwest China. Sustainability. 10, 3712-3737 (2018).

30. Li, C.H. et al. Risk assessment of water pollution sources based on an integrated k-means clustering and set pair analysis method in the region of Shiyan, China. Sci. Total Environ. 557, 307-316 (2016).

31. Wu, C.G. et al. Regional water resource carrying capacity evaluation based on multi-dimensional precondition cloud and risk matrix coupling model. Sci. Total Environ. 710, 1016-1025, (2020).

32. Zhao, K. An uncertain multi-attribute decision-making model and algorithm based on set-pair analysis. J. Intell. Syst. 5, 41-50 (2010).

33. Ruge, B. Risk Matrix as Tool for Risk Assessment in the Chemical Process Industries. Probabilistic Safety Assessment and Management. Springer, London. 2004.

\section{Funding}

This work is financially supported by the National Natural Science Foundation of China (Grant No. 42071278), the National Key R\&D Program of China (Grant No. 2017YFC0404600), the Fundamental Research Funds for the Central Universities of China (Grant No. B200204018). The authors are grateful to the anonymous reviewers and editors for their valuable comments and suggestions.

\section{Authors Contributions}

T.D. wrote the main manuscript text. J.C. offered the conceptualization and formal analysis. And M.L. provide methodology and editing. All authors reviewed the manuscript.

\section{Competing interests}

The authors declare no competing interests.

\section{Additional information}




\section{Supplementary Information}

Correspondence and requests for materials should be addressed to J.F.C 


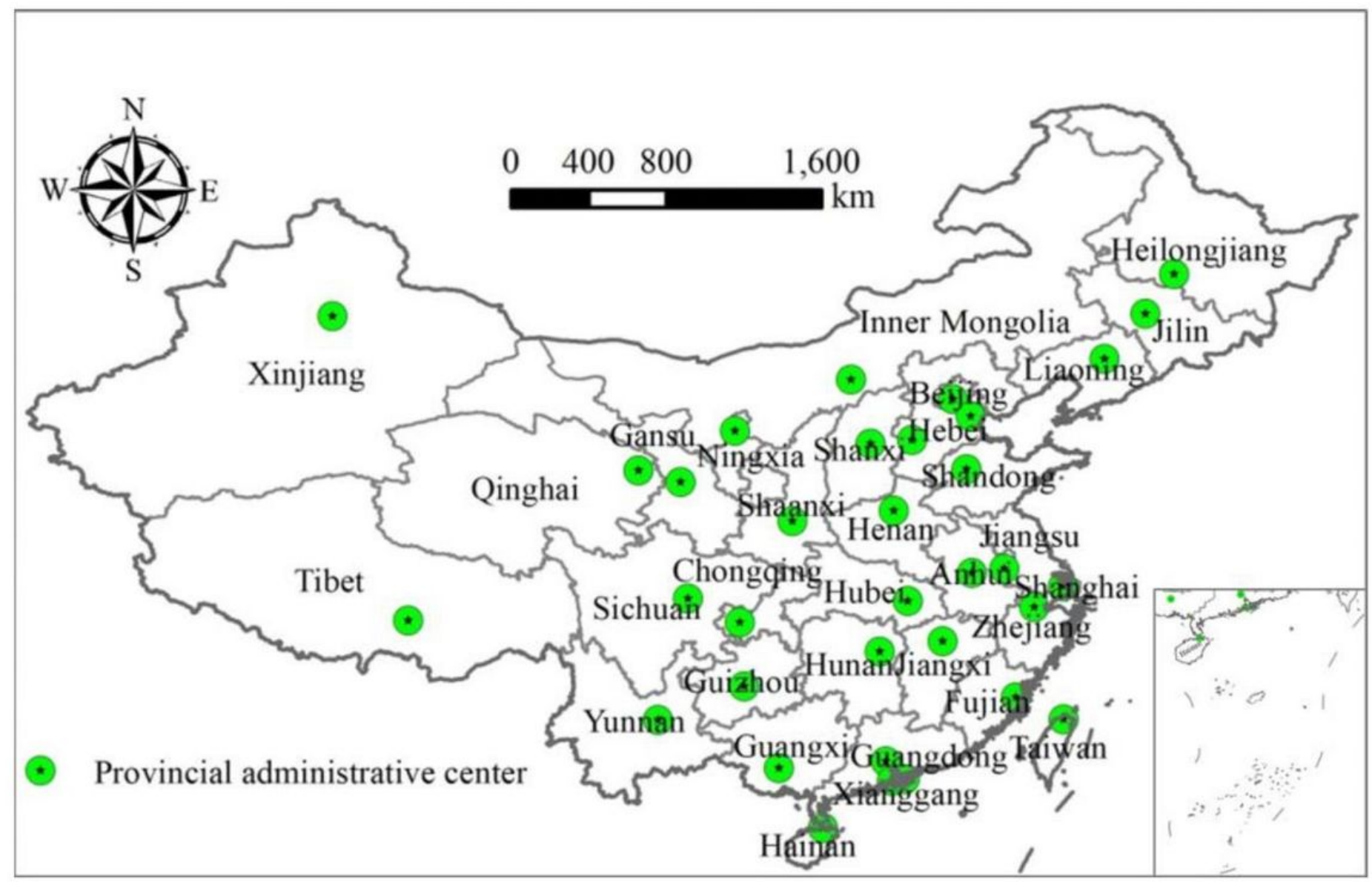

\section{Figure 1}

Geographic location of China Note: The designations employed and the presentation of the material on this map do not imply the expression of any opinion whatsoever on the part of Research Square concerning the legal status of any country, territory, city or area or of its authorities, or concerning the delimitation of its frontiers or boundaries. This map has been provided by the authors. 
Feedback

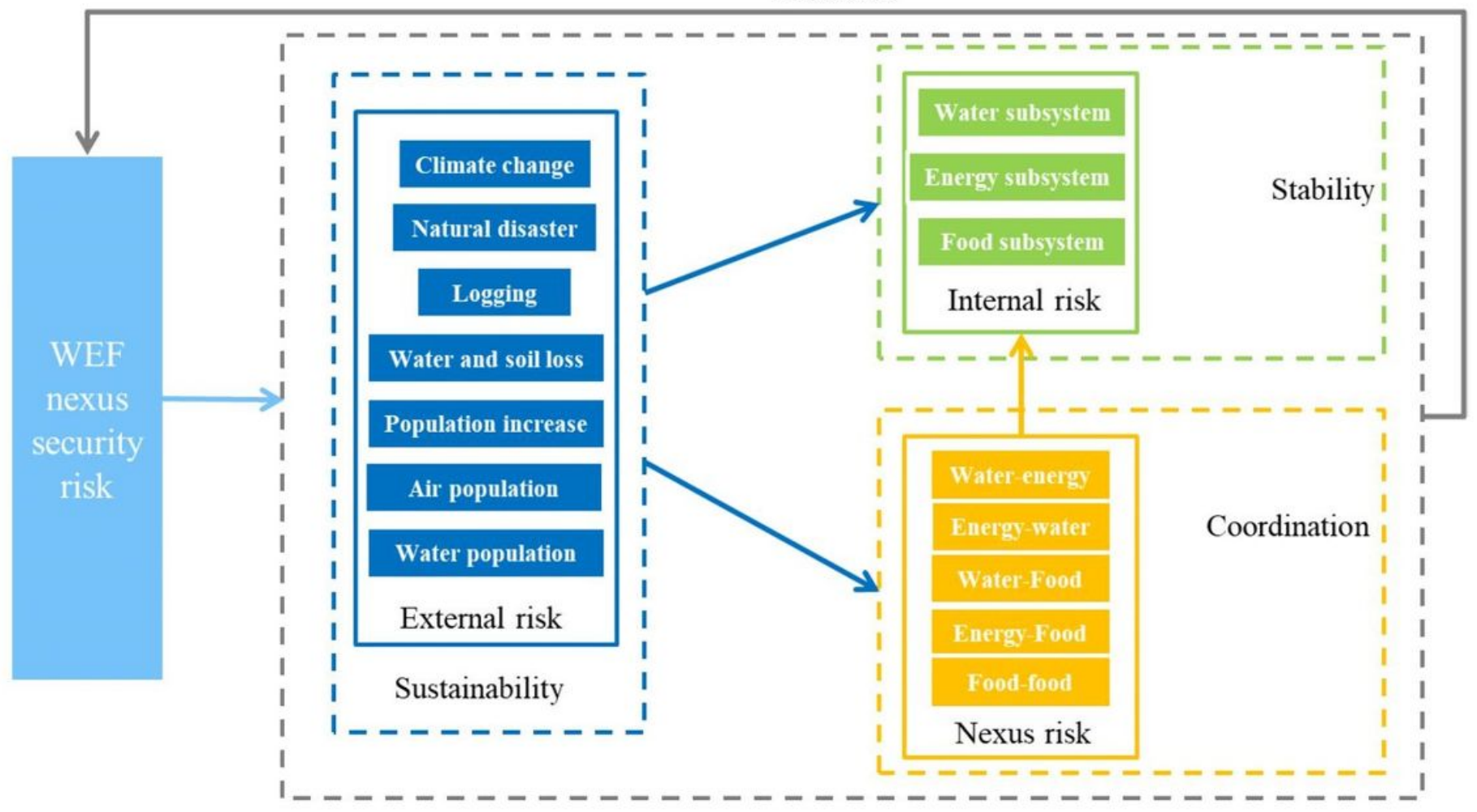

Figure 2

The concept diagram of WEF-R
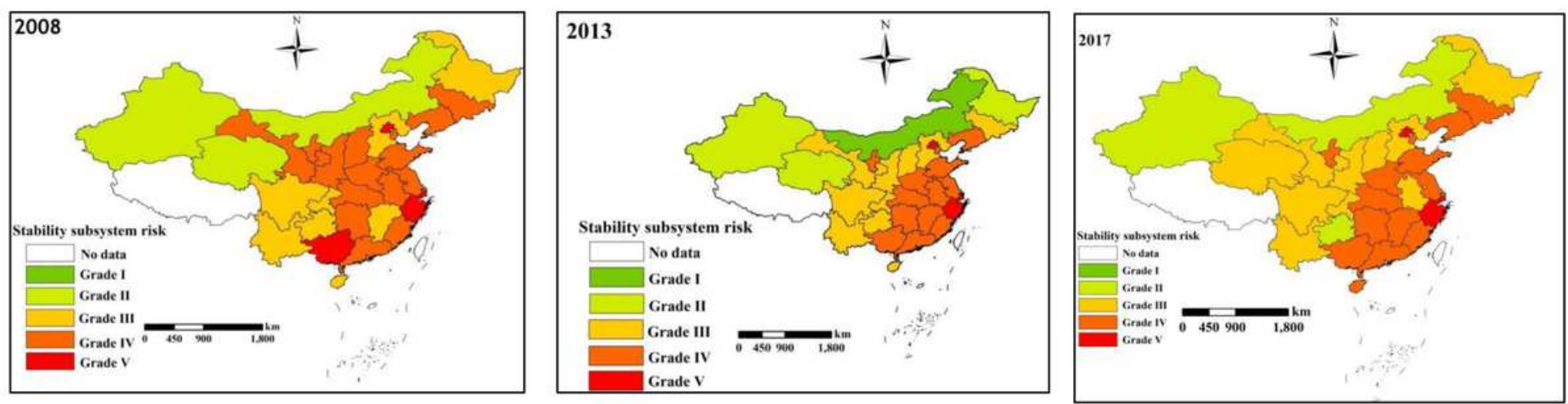

Figure 3

The spatial distribution of risk level of WEF stability subsystem in 30 provinces of China in 2008, 2013, and 2017 Note: The designations employed and the presentation of the material on this map do not imply the expression of any opinion whatsoever on the part of Research Square concerning the legal status of any country, territory, city or area or of its authorities, or concerning the delimitation of its frontiers or boundaries. This map has been provided by the authors. 

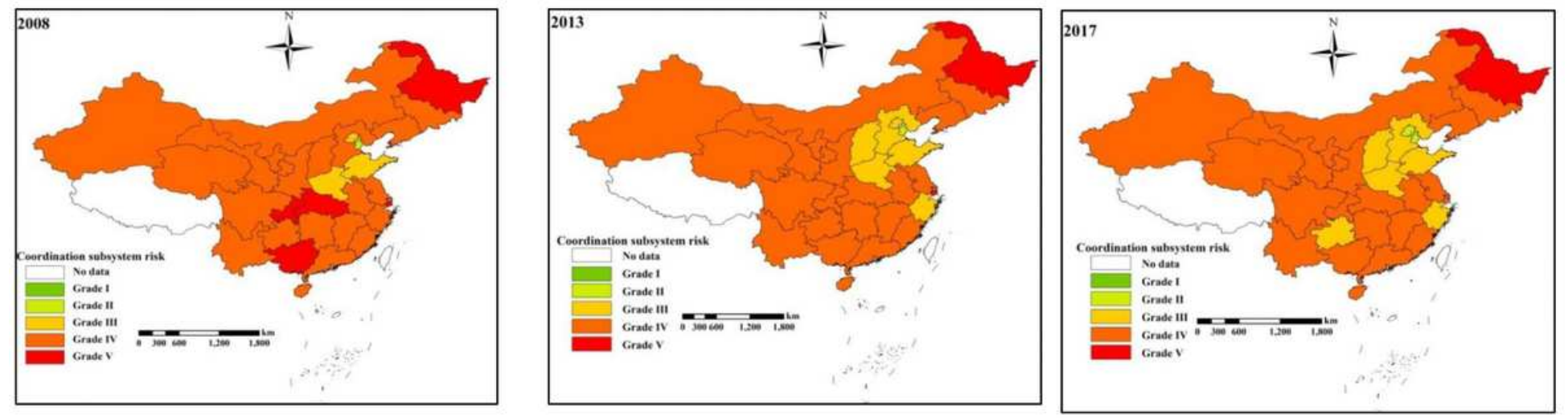

\section{Figure 4}

The spatial distribution of risk level of WEF coordination subsystem in 30 provinces of China Note: The designations employed and the presentation of the material on this map do not imply the expression of any opinion whatsoever on the part of Research Square concerning the legal status of any country, territory, city or area or of its authorities, or concerning the delimitation of its frontiers or boundaries. This map has been provided by the authors.
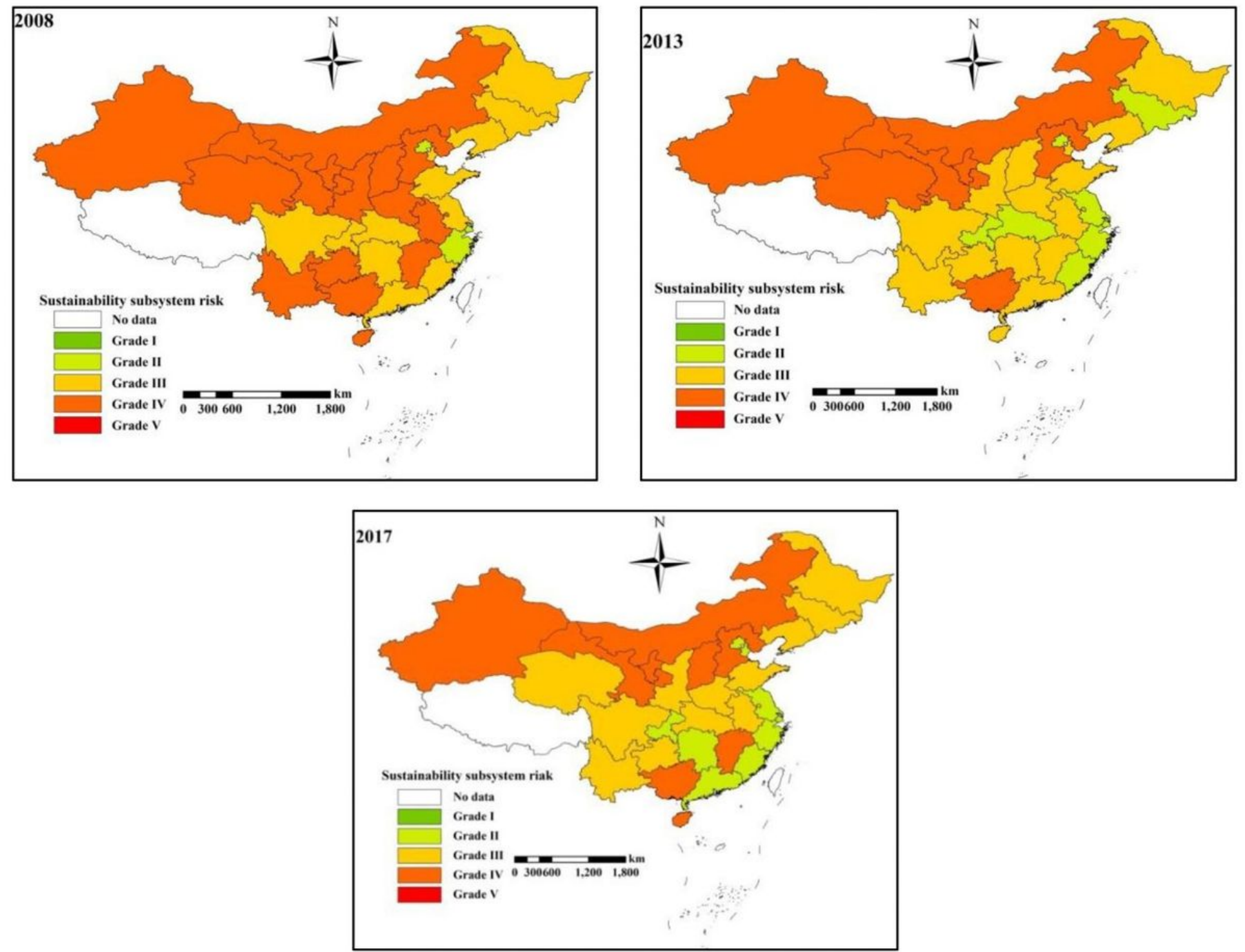


\section{Figure 5}

The spatial distribution of risk level of WEF sustainable subsystem in 30 provinces of China Note: The designations employed and the presentation of the material on this map do not imply the expression of any opinion whatsoever on the part of Research Square concerning the legal status of any country, territory, city or area or of its authorities, or concerning the delimitation of its frontiers or boundaries. This map has been provided by the authors.
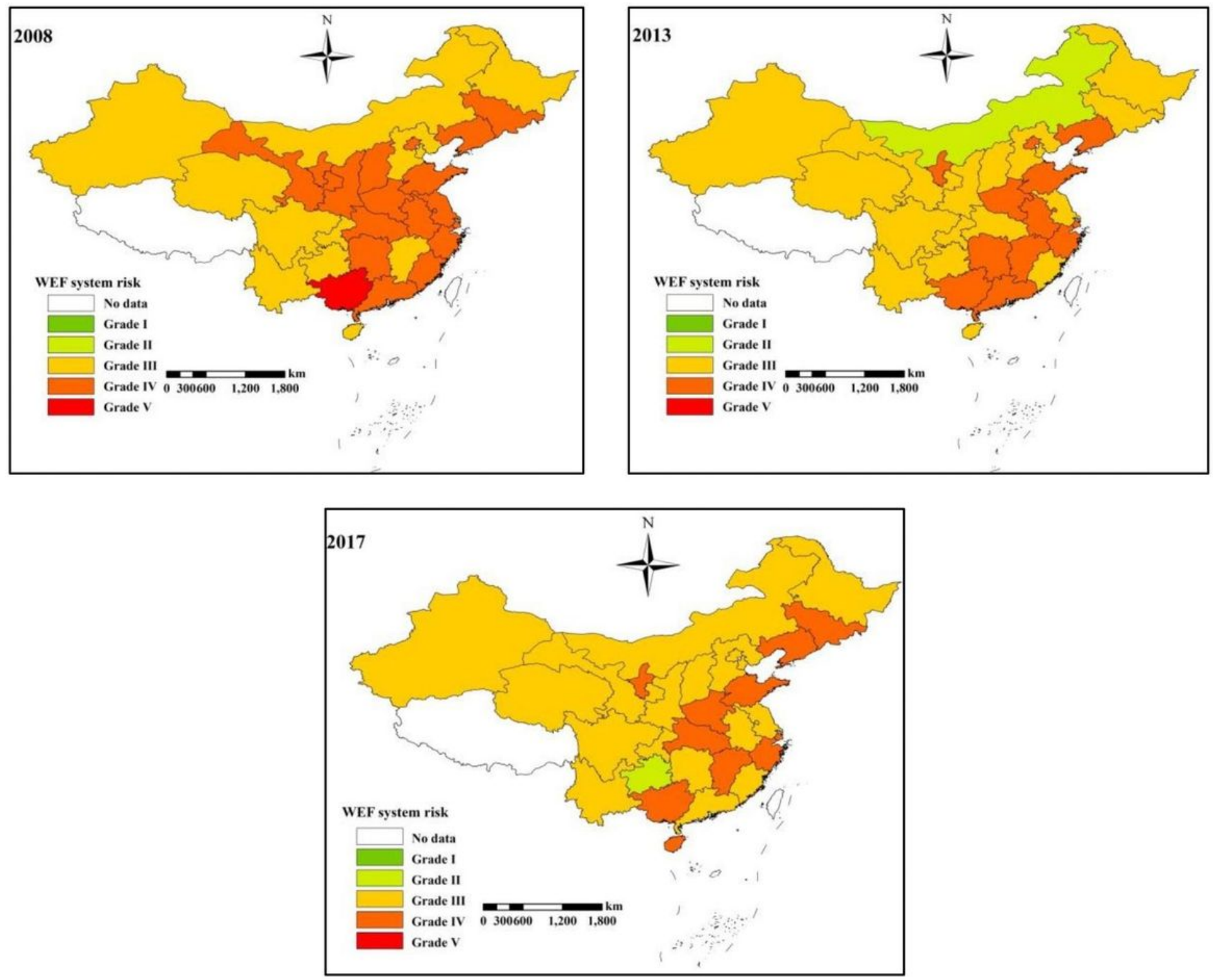

\section{Figure 6}

The spatial distribution of WEF-R levels in 30 provinces of China Note: The designations employed and the presentation of the material on this map do not imply the expression of any opinion whatsoever on the part of Research Square concerning the legal status of any country, territory, city or area or of its authorities, or concerning the delimitation of its frontiers or boundaries. This map has been provided by the authors. 


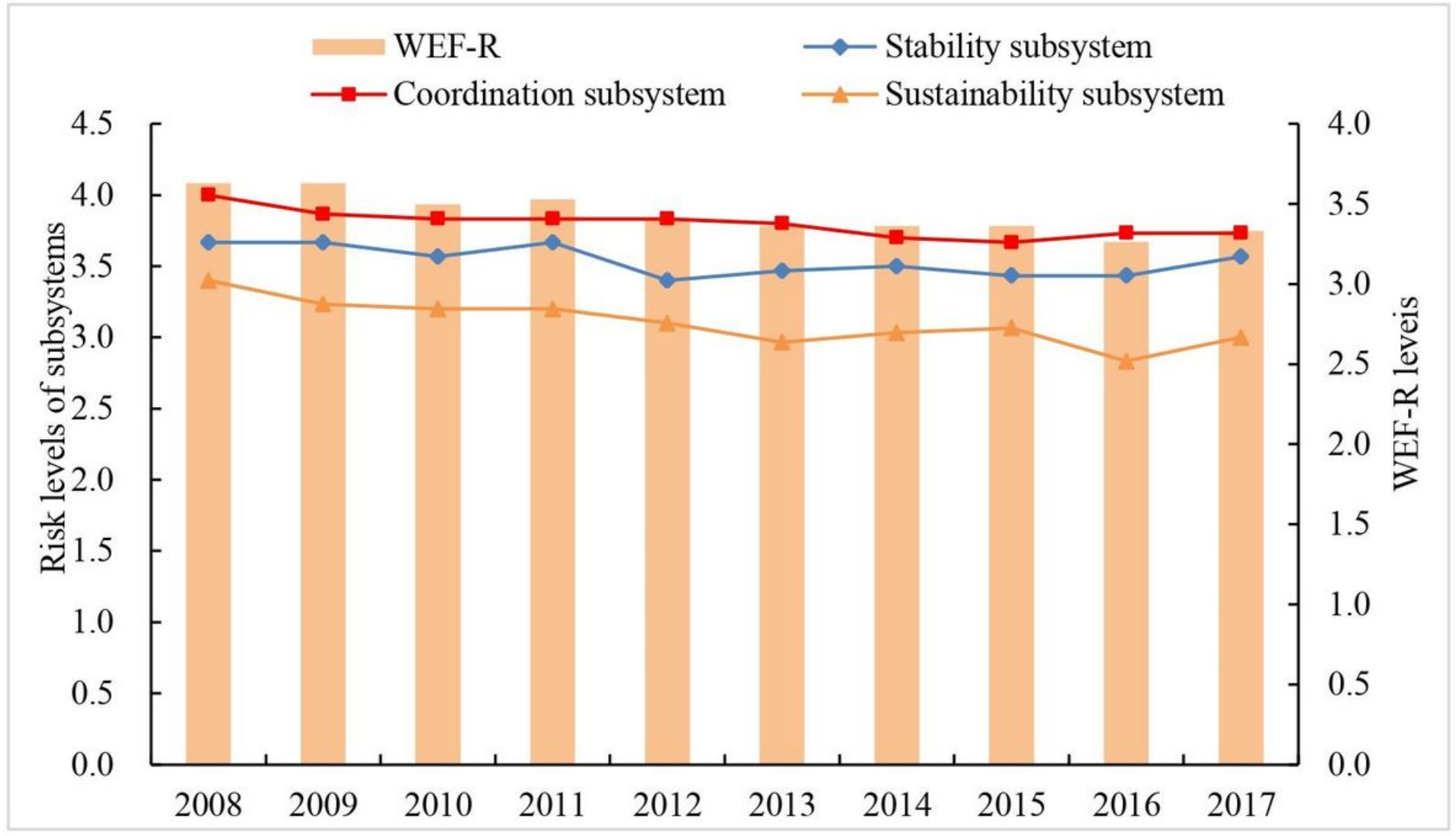

Figure 7

The change trend of risk levels of three subsystems and WEF-R in China from 2008 to 2017

\section{Supplementary Files}

This is a list of supplementary files associated with this preprint. Click to download.

- Supplementarylnformation.docx 